\title{
Mesophotic Coral Ecosystems of the Great Barrier Reef Are Understudied and Underexplored
}

\author{
Gal Eyal ${ }^{1,2 *}$, Jack H. Laverick ${ }^{3}$, Pim Bongaerts ${ }^{4}$, Oren Levy² and John M. Pandolfi' \\ 'ARC Centre of Excellence for Coral Reef Studies, School of Biological Sciences, The University of Queensland, Brisbane, \\ QLD, Australia, ${ }^{2}$ The Mina \& Everard Goodman Faculty of Life Sciences, Bar-llan University, Ramat Gan, Israel, ${ }^{3}$ Department \\ of Mathematics and Statistics, University of Strathclyde, Glasgow, United Kingdom, ${ }^{4}$ California Academy of Sciences, \\ San Francisco, CA, United States
}

\section{OPEN ACCESS}

Edited by:

Yehuda Benayahu,

Tel Aviv University, Israel

Reviewed by:

Michael S. Studivan,

University of Miami, United States

Dominic A. Andradi-Brown,

World Wildlife Fund, United States

Vianney Denis,

National Taiwan University, Taiwan

${ }^{*}$ Correspondence:

Gal Eyal

gal4596@gmail.com

Specialty section:

This article was submitted to Coral Reef Research,

a section of the journal

Frontiers in Marine Science

Received: 29 October 2020

Accepted: 20 January 2021

Published: 11 February 2021

Citation:

Eyal G, Laverick JH, Bongaerts $P$,

Levy O and Pandolfi JM (2021) Mesophotic Coral Ecosystems of the Great Barrier Reef Are Understudied

and Underexplored.

Front. Mar. Sci. 8:622856.

doi: 10.3389/fmars.2021.622856
Mesophotic coral ecosystems (MCEs) are characterized by the presence of photosynthetically active organisms such as corals and algae, and associated communities at depths ranging from 30 to $150 \mathrm{~m}$ in tropical and subtropical regions. Due to the increased awareness of the potential importance of these reefs as an integral part of coral reef ecosystems (i.e., deep reef refuge, specialized biodiversity, transition zone between shallow and deep-sea environments, and recreational and intrinsic values), interest from the scientific community has grown around the world over the last two decades. Several nations have already made management declarations and started to extend marine protected areas and fishery management to MCEs. The estimated area of Australian MCEs is likely equivalent to that of shallow reef ecosystems down to $30 \mathrm{~m}$; however, Australian MCEs attract limited research effort compared to other major coral reef regions around the world. In this perspective, we briefly explore the reasons for this scarcity of research on mesophotic ecosystems of the Great Barrier Reef (GBR) of Australia (e.g., strict diving regulations, new researchers' involvement, and logistics and cost). At present, research efforts on the mesophotic ecosystems of the GBR are in decline and if this trajectory is maintained, the global disparity in knowledge between MCEs near Australia and those from the other main coral reef regions worldwide will sharpen deeply. We call for action from the research community, grant agencies, and decision-makers toward a wider understanding of these important ecosystems in Australia.

Keywords: deep coral reefs, deep reef refuge hypothesis, Australia, Red Sea, prioritize research, management needs, trend projection, Holt-Winters model

\section{INTRODUCTION}

Australian coral reefs in general, and the Great Barrier Reef (GBR) in particular, have been studied extensively for almost a century. Pioneers explored these reefs in the historic 19281929 GBR expedition (Yonge, 1930) and the GBR became one of the most prestigious locations for coral reef studies (Day and Dobbs, 2013). The Australian Coral Reef Society (ACRS) was established in 1922 to protect the GBR and is considered the worlds' oldest organization concerned with the study and conservation of coral reefs (ACRS, 2020). Coral reefs in the region are still at the forefront of global research, with 135-195 papers published in the Web of Science Core Collection (WOS, 2020) every year (search terms: [coral] and 
[Australia]; 2010-2019). Those trends are on par with the Caribbean Sea (178-253 publications) and the Red Sea (93189 publications).

Mesophotic coral ecosystems (MCEs) have never been the main focus of GBR researchers (apart from a very few dedicated researchers), even though over the last decade there has been a bloom in mesophotic studies worldwide (Figure 1). While the ecological study of MCEs historically started in the Marshall Islands, Jamaica, Cuba, and Hawaii (reviewed in Pyle and Copus, 2019) in the 1960s-70s and in the Red Sea in the early 1980s (reviewed in Fricke, 1996), research at mesophotic depths on the GBR only started in the mid-1980s. In fact, very few mesophotic studies were published from the GBR until 2011, with a sharp increase to 10 publications that year (Bongaerts et al., 2019). Unfortunately, this relatively high publication output has not been sustained.

In this perspective, we forecast the future trends of mesophotic ecosystem studies and the involvement of researchers in studying these ecosystems around the main coral reef regions of the world. In addition, we discuss the possible reasons for the disparities in these trends between the GBR and the other major coral reef regions around the world.

\section{METHODS AND RESULTS}

\section{Global Distribution of Mesophotic Studies}

A concerted effort has been underway by mesophotic researchers to comprehensively collate both the historical and contemporary literature on mesophotic reefs into a database called Mesophotic.org (Bongaerts et al., 2019). This curated resource is openly available and allows us to quantify trends in the literature (Laverick et al., 2016, 2018; Turner et al., 2017; Lesser et al., 2019). We have divided the mesophotic literature into four major coral reef ecoregions: (I) the Red Sea, (II) the GBR including the Coral Sea, (III) the Indo-Pacific region, and (IV) the Tropical Western Atlantic (TWA) (Figure 1). These ecoregions were also chosen based on regional influences of closed-by nation or several nations on the coral reef research in the area. While the first two ecoregions, the Red Sea and the GBR, have been studied almost entirely by a single nation, the other two ecoregions, the Indo-Pacific and TWA, represent a wider area and are exposed to multinational influences. Using the programming language $\mathrm{R}$ ( $\mathrm{R}$ Core Team, 2013) and the tidyverse packages (Wickham et al., 2019), we summarized the meta-data in Mesophotic.org into annual time series of publications and unique first authors by region.

\section{Projected Trends in the Near Future}

Records of mesophotic publications started in the beginning of the 1960s with a small number of studies each year until the 1980s. Since 2010, publication rates accelerated over all regions. This can be attributed to the notable influence of the "International Workshop to Prioritize Research and Management Needs for Mesophotic Coral Ecosystems" in 2008 (Puglise et al., 2009) with mesophotic-specific funding for American-based territories that came from the National Oceanic and Atmospheric Association in the following years (e.g., NOAA, 2011, 2012, 2019). In the Red Sea, this increase came half a decade later and was partly driven by the "Second International Mesophotic Coral Ecosystems Workshop" in 2014 (Loya et al., 2016).

Analyses were performed on the individual time series for each coral reef region. We used the forecast package (Hyndman and Khandakar, 2007; Hyndman et al., 2018) in R to perform Holt-Winter's filtering (Winters, 1960; Holt, 2004) without a seasonal (gamma) component as our time series are annual. We then projected how these trends in yearly new publications and unique first authors may change over a 5-year prediction

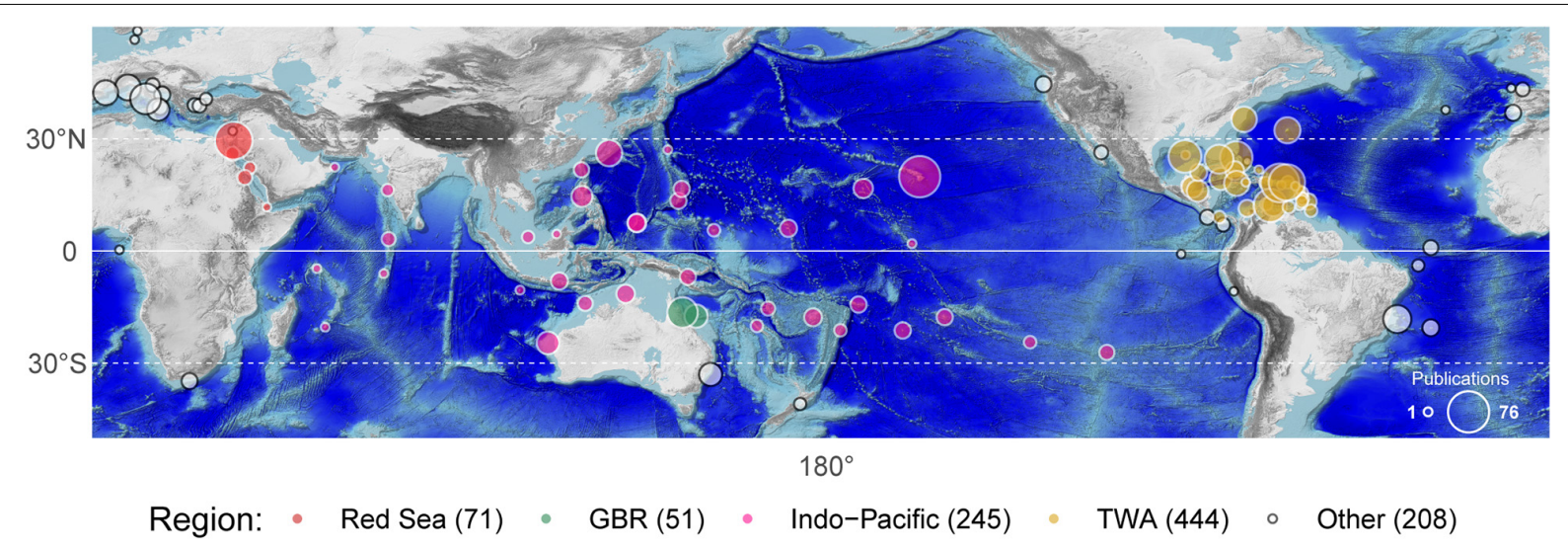

FIGURE 1 | Global distribution of mesophotic coral ecosystem studies across regions. Bubbles represent specific study locations, colored by region [red-Red Sea; green-Great Barrier Reef (GBR); pink-Indo-Pacific; and yellow-Tropical Western Atlantic (TWA)]. White bubbles indicate MCE sites not included in the analyses as they fell outside of our principal regions of interest (tropical coral reefs). The size of the bubble indicates the total number of publications from 1 to 76 as indicated by the scale on the bottom-right. Numbers in brackets, in the bottom region legend, indicate the total number of publications for the region. Publication data were collected from Mesophotic.org database for the period of 1960-2019 (Bongaerts et al., 2019). Base-map was derived from the GEBCO global bathymetry model (GEBCO Compilation Group, 2020). 
horizon (Figure 2). We found increases in the number of new publications published each year in all regions except the GBR (Figure 2A top). In addition, we forecast a slight decline of 0.5 in unique first authors over our forecast window to 2024 for the GBR compared to 2.4 more first authors in the Red Sea at the same period (Figure 2A bottom). The larger and multinational Indo-Pacific and TWA regions are the main sources of studies on mesophotic reefs, publishing more papers from more researchers than the Red Sea and the GBR. Nonetheless, both the IndoPacific and TWA are forecasted to continue to increase both metrics, though not as rapidly as the Red Sea (Figure 2). When considering the average values over the last decade alongside predicted rates of change, the GBR stands alone as a region with lower-than-average output and no growth (Figure 2B). We describe the other small region, the Red Sea, as an emerging region as it has below average output, which is similar to the GBR, but is growing the fastest of any region. Last, both the Indo-Pacific and TWA have above average output, as expected from larger regions, but also continue to grow.

\section{DISCUSSION}

Mesophotic coral ecosystems are the link between shallow reefs and deep-sea habitats, and host diverse depth-generalist and depth-specialist taxa, with many unique taxa as well (Eyal and Pinheiro, 2020 and the references within). New species are discovered on MCEs at a high rate, but reviling biodiversity of most regions/depths is not possible yet due to the lack of data (Pyle and Copus, 2019; Turner et al., 2019). Marine spatial planning and adaptive management based on empirical data is needed to secure the health and protect these ecosystems. The motivation for this perspective piece is to highlight the possible causes for the disproportionately low levels of mesophotic research on the GBR, given it is significance for coral reef research more generally. We also want to encourage the local and research communities, funding agencies, NGOs, and governmental authorities in Australia to bring forward mesophotic studies from the world's largest reef system. With overall decline in the health of shallow reefs over the last decades, it is important to understand the value and role of MCEs on the GBR, as well as in the context of reef ecosystems globally. Recent studies showed major shifts in cover and size-structure of corals along shallow reefs of the GBR over the last 30 years (e.g., Dietzel et al., 2020), but knowledge about these changes in MCEs is virtually non-existent for the GBR. Though historical decline has been caused by a host of factors associated with human interaction (Pandolfi et al., 2003), the current cause of this coral decline is anthropogenic climate change and recurrent bleaching events (Hughes et al., 2017, 2018a,b). The effects of heat and light stress on corals generally decrease with depth (Lesser et al., 2009) and although there is some evidence of bleaching and mortality from MCEs, this mortality is significantly lower than in shallow reefs (Frade et al., 2018).

While the rest of the world is expected to produce increasing numbers of new publications and involvement of new researchers (as measured by unique first authors per year), our forecasts suggest a stagnation of the GBR research community and even

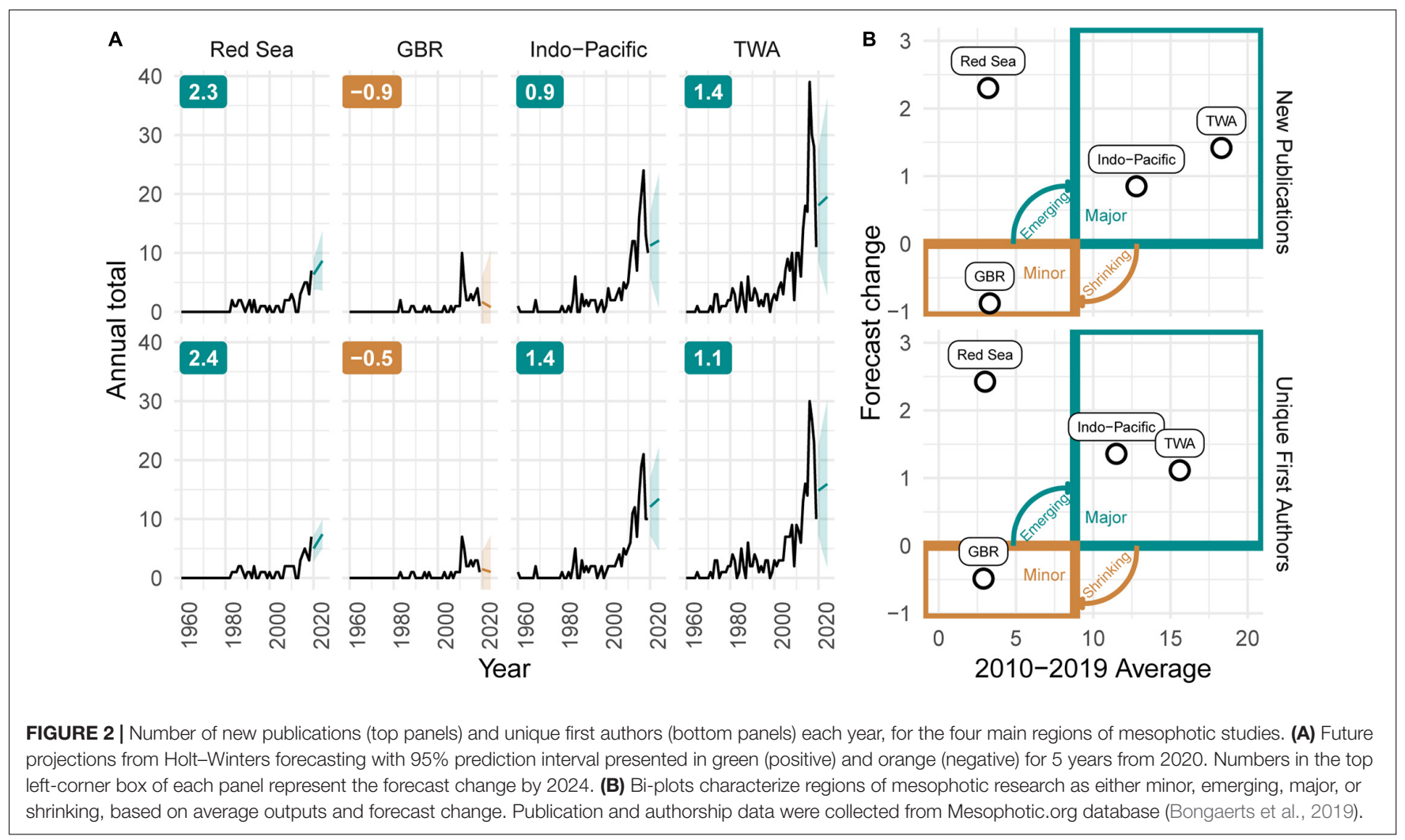


a decline in their research efforts on MCEs. These projections are cause for concern as MCEs may play an integral role in the ecological function of coral reef ecosystems (Bridge et al., 2013). Understanding the whole coral reef ecosystem is vital for effective management and future conservation efforts (Rocha et al., 2018).

There are several reasons for the lack of growth in mesophotic research efforts on the GBR. Scientific diving in Australia is covered by the occupational divers AS/NZS 2299.2 regulations, which currently limit activity to a maximum depth of $39 \mathrm{~m}$ and prevent the use of closed-circuit rebreathers and decompression dives (Benjamin and MacKintosh, 2016). These regulations curtail the ability to conduct scientific diving at mesophotic depths. In most parts of the other three major regions for which we produced forecasts, the regulation of scientific diving is conducted under the American Association of Scientific Diving (AAUS) standards that specifically allow all of the above activities, and are regularly updated to include newly developed technologies and procedures (Pyle, 2019). Additionally, conducting any coral reef research in most parts of Australia is costly. This is partly because of the geographical distance and isolation of MCEs, with many of the more developed systems occurring on the edge of the continental shelf. Mesophotic research is already considered costly due to more complicated logistics and technological requirements in contrast to shallow reef studies (Armstrong et al., 2019; Pyle, 2019), and is not affordable for most researchers.

Without a doubt, climate change is the most urgent and important topic for coral reef research and society in general. The devastating effects of global warming on coral reefs are known to diminish with depth, although they are not absent from the mesophotic zone (Frade et al., 2018; Rocha et al., 2018). In Australia, anthropogenic climate change is a major concern on a daily basis (Hughes et al., 2017). Investing more effort in studying mesophotic ecosystems or conducting surveys and experiments with a wide depth range could be fruitful for protecting coral reefs for two reasons. Understanding the impacts of global change and other stressors such as overfishing, urbanization, and sedimentation on those unique ecosystems will first promote protection and management and second help to verify whether reefs from deeper depths can provide refuge to reef organisms from shallower depths (Bongaerts et al., 2010; Bongaerts and Smith, 2019).

In this perspective, we explored some possible reasons for the scarcity of research on the GBR mesophotic ecosystems (e.g., strict diving regulations, logistics, and cost). We further called upon the local and research communities, granting agencies, NGOs, and national authorities to act for the enhancement of mesophotic studies globally, with particular emphasis on efforts in Australia. In addition, we recommend the following specific actions to facilitate mesophotic research in Australia:

1) To increase researchers' involvement, we recommend a review of the scientific diving regulations to allow safe, but feasible, scientific diving activity on MCEs in Australia, perhaps adopting similar protocols to those of the AAUS standards or joining the AAUS.
2) To design research that directly meets the management needs of MCE services, and inclusion in marine spatial planning and adaptive management (Day, 2008). To understand these needs, it is critical to obtain data on the distribution and diversity of mesophotic ecosystems and the ecosystem services they provide (Turner et al., 2019). For example, the Israeli Nature and Parks Authority are responding regularly to new discoveries of MCEs in the Red Sea and Mediterranean Sea by extending Nature Reserves and prioritize protection areas with high biodiversity or unique species (G. Eyal, per. com; Bridge et al., 2013). Although a relatively large part of the mesophotic waters of the GBR and Coral Sea areas are protected by marine parks (Parks, 2020), areas assigned high protection levels (e.g., pink-no entry zone and green-no collecting zone) are more common proportionally in shallow habitats (Bridge et al., 2013). This is likely because of the larger amounts of data available for justifying protection for shallow reefs in contrast to MCEs, rather than stakeholder pressure from external groups.

3) To encourage combining resources and cost sharing for shallow and mesophotic research. This can be accomplished by increasing the depth range of approved surveys and long-term monitoring. Local groups, NGOs, and governmental agencies should encourage collection depositions in museums. More, joint projects could be beneficial for shallow reef surveys and collections that could be done on the ascending time from deeper depths. Furthermore, specific grant support for MCEs research could facilitate the topic in Australia and encourage MCEs research in this region. These activities are required to create a strong foundation for mesophotic research on the GBR and the Coral Sea.

\section{DATA AVAILABILITY STATEMENT}

The original contributions presented in the study are included in the article/supplementary material. Further inquiries can be directed to the corresponding author/s.

\section{AUTHOR CONTRIBUTIONS}

GE, JL, OL, and JP conceived the idea of the study. GE, JL, and $\mathrm{PB}$ collected and processed the data. All authors wrote and revised the manuscript.

\section{FUNDING}

This project received funding from the European Union's Horizon 2020 Research and Innovation Program under the Marie Skłodowska-Curie grant agreement no. 796025.

\section{ACKNOWLEDGMENTS}

We thank the Mesophotic.org database for making their opensource dataset available for us. 


\section{REFERENCES}

ACRS (2020). Australian Coral Reef Society. Available online at: https:// australiancoralreefsociety.org/about/ (accessed October 16, 2020).

Armstrong, R. A., Pizarro, O., and Roman, C. (2019). "Underwater robotic technology for imaging mesophotic coral ecosystems," in Mesophotic Coral Ecosystems, eds T. C. L. Bridge, Y. Loya, and K. A. Puglise (Cham: Springer), 973-988. doi: 10.1007/978-3-319-92735-0_51

Benjamin, J., and MacKintosh, R. (2016). Regulating Scientific Diving and Underwater Archaeology: legal and historical considerations. Int. J. Naut. Archaeol. 45, 153-169. doi: 10.1111/1095-9270.12141

Bongaerts, P., Perez-Rosales, G., Radice, V. Z., Eyal, G., Gori, A., Gress, E., et al. (2019). Mesophotic. org: a repository for scientific information on mesophotic ecosystems. Database 2019:baz140. doi: 10.1093/database/baz140

Bongaerts, P., Ridgway, T., Sampayo, E., and Hoegh-Guldberg, O. (2010). Assessing the 'deep reef refugia'hypothesis: focus on Caribbean reefs. Coral Reefs 29, 309-327. doi: 10.1007/s00338-009-0581-x

Bongaerts, P., and Smith, T. B. (2019). "Beyond the "Deep Reef Refuge" hypothesis: a conceptual framework to characterize persistence at depth," in Mesophotic Coral Ecosystems, eds T. C. L. Bridge, Y. Loya, and K. A. Puglise (Cham: Springer), 881-895. doi: 10.1007/978-3-319-92735-0_45

Bridge, T. C., Hughes, T. P., Guinotte, J. M., and Bongaerts, P. (2013). Call to protect all coral reefs. Nat. Clim. Change 3, 528-530. doi: $10.1038 /$ nclimate 1879

Day, J. (2008). The need and practice of monitoring, evaluating and adapting marine planning and management-lessons from the Great Barrier Reef. Mar. Policy 32, 823-831. doi: 10.1016/j.marpol.2008.03.023

Day, J. C., and Dobbs, K. (2013). Effective governance of a large and complex crossjurisdictional marine protected area: Australia's Great Barrier Reef. Mar. Policy 41, 14-24. doi: 10.1016/j.marpol.2012.12.020

Dietzel, A., Bode, M., Connolly, S. R., and Hughes, T. P. (2020). Long-term shifts in the colony size structure of coral populations along the Great Barrier Reef. Proc. R. Soc. B 287:20201432. doi: 10.1098/rspb.2020.1432

Eyal, G., and Pinheiro, H. T. (2020). Mesophotic ecosystems: the link between shallow and deep-sea habitats. Diversity 12:411. doi: 10.3390/d12110411

Frade, P. R., Bongaerts, P., Englebert, N., Rogers, A., Gonzalez-Rivero, M., and Hoegh-Guldberg, O. (2018). Deep reefs of the Great Barrier Reef offer limited thermal refuge during mass coral bleaching. Nat. Commun. 9:3447. doi: 10 . 1038/s41467-018-05741-0

Fricke, H. (1996). "Deep-water exploration of the red sea by submersible," in Deep-Sea and Extreme Shallow-Water Habitats: Affinities and Adaptations, Biosystematics and Ecology Series, Vol. 11, eds F. Uiblein, J. Ott, and M. Stachowtisch, 67-89

GEBCO Compilation Group (2020). GEBCO 2020 Grid. Available online at: https: //www.gebco.net/data_and_products/gridded_bathymetry_data/

Holt, C. C. (2004). Forecasting seasonals and trends by exponentially weighted moving averages. Int. J. Forecast. 20, 5-10. doi: 10.1016/j.ijforecast.2003. 09.015

Hughes, T. P., Anderson, K. D., Connolly, S. R., Heron, S. F., Kerry, J. T., Lough, J. M., et al. (2018a). Spatial and temporal patterns of mass bleaching of corals in the Anthropocene. Science 359, 80-83. doi: 10.1126/science.aan8048

Hughes, T. P., Kerry, J. T., Álvarez-Noriega, M., Álvarez-Romero, J. G., Anderson, K. D., Baird, A. H., et al. (2017). Global warming and recurrent mass bleaching of corals. Nature 543, 373-377. doi: 10.1038/nature21707

Hughes, T. P., Kerry, J. T., Baird, A. H., Connolly, S. R., Dietzel, A., Eakin, C. M., et al. (2018b). Global warming transforms coral reef assemblages. Nature 556, 492-496. doi: 10.1038/s41586-018-0041-2

Hyndman, R. J., Athanasopoulos, G., Bergmeir, C., Caceres, G., Chhay, L., O’haraWild, M., et al. (2018). Forecast: Forecasting Functions for Time Series and Linear Models. Software, R Package. Available online at: https://pkg.robjhyndman.com/ forecast/

Hyndman, R. J., and Khandakar, Y. (2007). Automatic time series for forecasting: the forecast package for R. Paper Presented at the Monash Econometrics and Business Statistics Working Papers 6/0 (Clayton VIC: Monash University, Department of Econometrics and Business Statistics).

Laverick, J. H., Andradi-Brown, D. A., Exton, D. A., Bongaerts, P., Bridge, T. C., Lesser, M. P., et al. (2016). To what extent do mesophotic coral ecosystems and shallow reefs share species of conservation interest? Environ. Evid. 5:16. doi: 10.1186/s13750-016-0068-5

Laverick, J. H., Piango, S., Andradi-Brown, D. A., Exton, D. A., Bongaerts, P., Bridge, T. C., et al. (2018). To what extent do mesophotic coral ecosystems and shallow reefs share species of conservation interest? A systematic review. Environ. Evid. 7, 1-13. doi: 10.1186/s13750-018-0127-1

Lesser, M. P., Slattery, M., Laverick, J. H., Macartney, K. J., and Bridge, T. C. (2019). Global community breaks at $60 \mathrm{~m}$ on mesophotic coral reefs. Global Ecol. Biogeogr. 28, 1403-1416. doi: 10.1111/geb.12940

Lesser, M. P., Slattery, M., and Leichter, J. J. (2009). Ecology of mesophotic coral reefs. J. Exp. Mar. Biol. Ecol. 375, 1-8. doi: 10.1016/j.jembe.2009.05.009

Loya, Y., Eyal, G., Treibitz, T., Lesser, M. P., and Appeldoorn, R. (2016). Theme section on mesophotic coral ecosystems: advances in knowledge and future perspectives. Coral Reefs 35, 1-9. doi: 10.1007/s00338-016-1410-7

NOAA (2011). Ecology, Integrity and Status of Caribbean Mesophotic Coral Reefs. Available online at: https://coastalscience.noaa.gov/project/ecology-integritystatus-caribbean-mesophotic-coral-reefs/ (accessed October 16, 2020).

NOAA (2012). Investigating Mesophotic Coral Reefs in Hawaii [Online]. Available online at: https://coastalscience.noaa.gov/project/investigating-mesophoticcoral-reefs-hawaii/ (accessed October 16, 2020).

NOAA (2019). NOAA awards \$2.4 million for mesophotic coral ecosystem research in American Samoa [Online]. Available online at: https: //sanctuaries.noaa.gov/news/oct19/noaa-funds-mesophotic-coral-ecosystemresearch-american-samoa.html (accessed October 16, 2020).

Pandolfi, J. M., Bradbury, R. H., Sala, E., Hughes, T. P., Bjorndal, K. A., Cooke, R. G., et al. (2003). Global trajectories of the long-term decline of coral reef ecosystems. Science 301, 955-958. doi: 10.1126/science.1085706

Parks (2020). Australian Marine Parks [Online]. Australian Government. Available online at: https://parksaustralia.gov.au/marine/ (accessed October 16, 2020).

Puglise, K., Hinderstein, L. M., Marr, J., Dowgiallo, M. J., and Martinez, F. A. (2009). Mesophotic coral ecosystem research strategy International Workshop to Prioritize Research and Management Needs for Mesophotic Coral Ecosystems, Jupiter, Florida, 12-15 July, 2009. Jupiter, FL: NOAA,

Pyle, R. L. (2019). “Advanced technical diving," in Mesophotic Coral Ecosystems, eds T. C. L. Bridge, Y. Loya, and K. A. Puglise (Cham: Springer), 959-972. doi: 10.1007/978-3-319-92735-0_50

Pyle, R. L., and Copus, J. M. (2019). "Mesophotic coral ecosystems: introduction and overview," in Mesophotic Coral Ecosystems, eds T. C. L. Bridge, Y. Loya, and K. A. Puglise (Cham: Springer), 3-27. doi: 10.1007/978-3-319-92735-0_1

R Core Team (2013). R: A Language and Environment for Statistical Computing. Vienna: R Foundation for Statistical Computing. Available online at: https: //www.R-project.org/

Rocha, L. A., Pinheiro, H. T., Shepherd, B., Papastamatiou, Y. P., Luiz, O. J., Pyle, R. L., et al. (2018). Mesophotic coral ecosystems are threatened and ecologically distinct from shallow water reefs. Science 361, 281-284. doi: 10.1126/science. aaq1614

Turner, J. A., Andradi-Brown, D. A., Gori, A., Bongaerts, P., Burdett, H. L., Ferrier-Pagès, C., et al. (2019). "Key questions for research and conservation of mesophotic coral ecosystems and temperate mesophotic ecosystems," in Mesophotic Coral Ecosystems, eds T. C. L. Bridge, Y. Loya, and K. A. Puglise (Cham: Springer), 989-1003. doi: 10.1007/978-3-319-92735-0_52

Turner, J. A., Babcock, R. C., Hovey, R., Kendrick, G. A., and Degraer, S. (2017). Deep thinking: a systematic review of mesophotic coral ecosystems. ICES J. Mar. Sci. 74, 2309-2320. doi: 10.1093/icesjms/fsx085

Wickham, H., Averick, M., Bryan, J., Chang, W., Mcgowan, L. D. A., François, R., et al. (2019). Welcome to the Tidyverse. J. Open Source Softw. 4:1686. doi: 10.21105 /joss. 01686

Winters, P. R. (1960). Forecasting sales by exponentially weighted moving averages. Manag. Sci. 6, 324-342. doi: 10.1287/mnsc.6.3.324

WOS. (2020). Web of Science Core Collection. Philadelphia, PA: ClarivateAnalytics. Yonge, C. M. (1930). A Year on the Great Barrier Reef: the Story of Corals \& of the Greatest of Their Creations. New York, NY: Putnam.

Conflict of Interest: The authors declare that the research was conducted in the absence of any commercial or financial relationships that could be construed as a potential conflict of interest.

Copyright (C) 2021 Eyal, Laverick, Bongaerts, Levy and Pandolfi. This is an openaccess article distributed under the terms of the Creative Commons Attribution License (CC BY). The use, distribution or reproduction in other forums is permitted, provided the original author(s) and the copyright owner(s) are credited and that the original publication in this journal is cited, in accordance with accepted academic practice. No use, distribution or reproduction is permitted which does not comply with these terms. 